Ann Bernadette G. Sunga, MD

Samantha S. Castañeda, MD

Department of Otorhinolaryngology

Head and Neck Surgery

Rizal Medical Center

\section{A Second Branchial Cleft Cyst Presenting as a Dumbbell-Shaped Anterior Neck Mass}

Branchial cleft anomalies are among the most common causes of congenital anterior neck masses in the pediatric population. They present as epithelial-lined, single cysts. ${ }^{1,2}$ The definitive management is surgical excision. ${ }^{3}$ However, failure to remove the entire cyst and tract may lead to recurrence of the mass. ${ }^{3}$

Unusual presentations of this condition may lead to incomplete excision if inadequately evaluated. There is a scarcity of material documenting atypical presentations of branchial cleft anomalies-- in particular, presentation as 2 distinct cysts in one region. In our literature search of PubMed, Google Scholar and HERDIN using the terms: "congenital mass," "branchial cleft cyst," and "multiple cysts," only 3 similar cases were found.

We report a case of a second branchial cleft anomaly presenting as a dumbbell-shaped mass (two cystic structures, connected by a tubular structure) in the right lateral neck, the subsequent management and outcomes.

\section{CASE REPORT}

A 2-year-old girl presented with a $0.5 \mathrm{~cm} \times 0.5 \mathrm{~cm}$ right anterior neck mass since birth which was soft, non-tender and movable with no other associated complaints. They consulted at a government institution where the parents were reassured that the mass was "excess fat." No further investigations were done.

Three months prior to consult, after a bout of upper respiratory tract infection (URTI), the caregivers noted an increase in size of the mass to approximately $4 \times 4 \mathrm{~cm}$ which was still soft but tender and erythematous with a central draining sinus. She was seen at our clinic and was diagnosed with an infected branchial cleft cyst type II, right. She was admitted and given appropriate antibiotics. Physical examination showed the mass located at the level of the thyroid notch, anterior to the medial border of the sternocleidomastoid (SCM) muscle, immediately superior to the right clavicular head. (Figure 1)

Contrast enhanced computed tomography (CT) scans of the neck showed thin-walled, sharply circumscribed, minimally enhancing cystic masses at the right upper jugular region, anterior to the sternocleidomastoid muscle, $1.5 \times 2.4 \times 1.8 \mathrm{~cm}$ (Figure 2A), mid jugular region along the anterior margin of sternocleidomastoid muscle measuring, $0.6 \times 1.2 \times 0.8 \mathrm{~cm}$, and in the lower jugular region anterior to the thyroid gland measuring $2.0 \times 3.1 \times 2.2 \mathrm{~cm}$. (Figure 2B) The cystic 


\section{FEATURED GRAND ROUNDS}

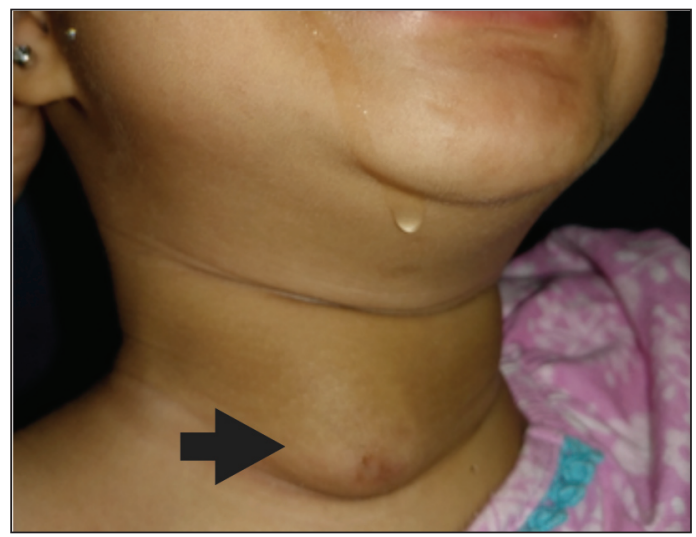

Figure 1. Right anterior neck mass with a draining sinus
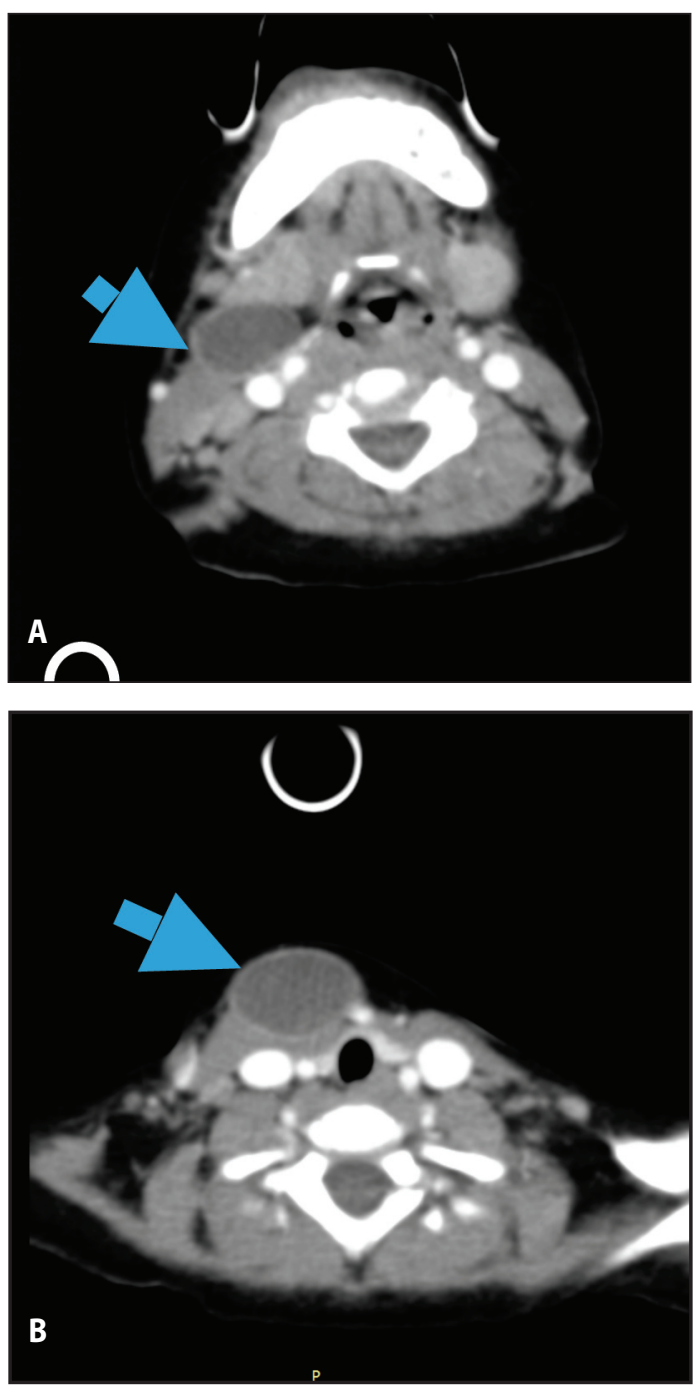

Figure 2. Contrast- enhanced CT-scan of the neck, axial view showing thinwalled, minimally enhancing cystic structures, A. Upper jugular region B. Lower jugular region

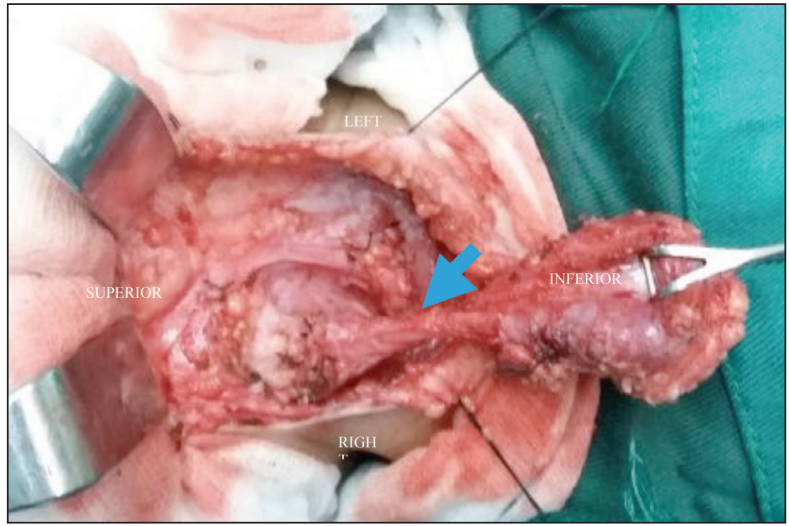

Figure 3. Intraoperative findings: superficial cyst, anterior to the sternocleidomastoid muscle (SCM) connected by a tract to a second cyst, deep into the SCM

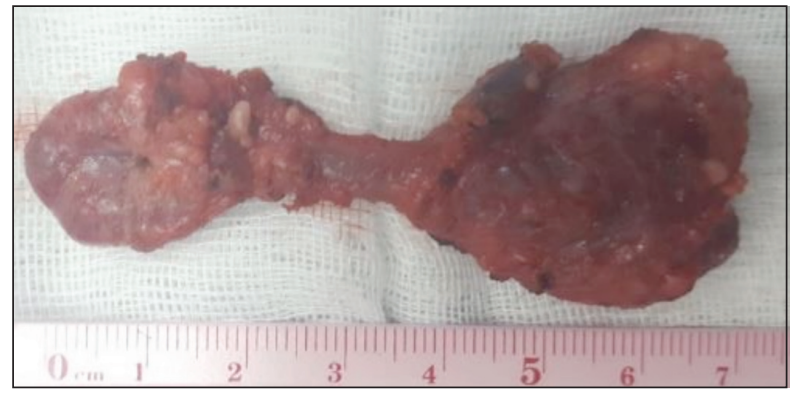

Figure 4. Excised mass

masses showed no obvious communications with each other and with the pyriform sinus and laryngeal ventricle. There was no tumoral encasement of the vessels and cervical trachea or evident invasion of vascular structures.

A month after resolution of the infection, the patient underwent surgery. Intraoperatively, there were 2 masses observed, the first mass more superficial located anterior to the SCM and upon further exploration there was a bottle-neck narrowing and another cystic structure located deep to the right SCM. (Figure 3) The excised mass was composed of 2 cystic structures attached to one another that still appeared to have different compartments. (Figure 4) The second cyst was followed superiorly until the upper jugular region at the level of the body of the mandible ending in a blind sac. No further exploration was done and no dye was infiltrated into the cyst or tract.

Histopathologic studies showed a cyst wall lined with squamous cells. (Figure 5) Higher magnification showed the inner lining with lymphoid aggregates and possible chronic inflammation as evidenced by infiltration of mononuclear cells. (Figure 6)

On latest follow-up 1 month post-operatively, the patient had good wound healing with no persistent draining sinus. 


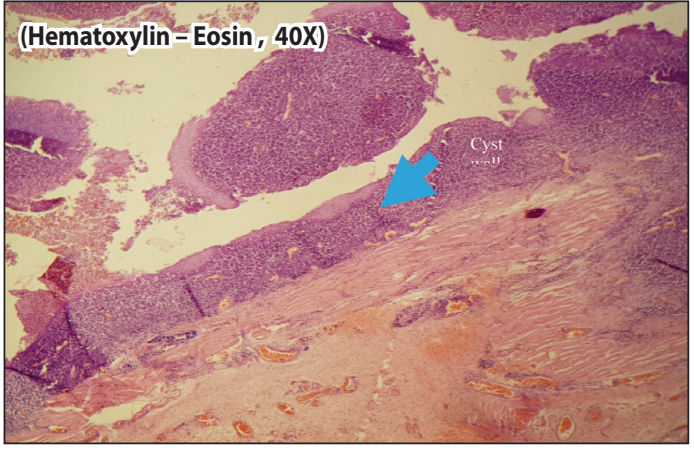

Figure 5. Scanner view of the excised mass under $\mathrm{H}$ \& E staining, showing an epithelium-lined cyst

\section{DISCUSSION}

Branchial cleft anomalies are congenital epithelium-lined cysts theorized to result from entrapment of elements of the cervical sinus of His. 'Clinically, they can present as a non-painful, fluctuant and single mass identified at birth or as late as adulthood when the mass becomes infected and forms an abscess during episodes of URTI. ${ }^{14}$ These factors were noted to be consistent with our patient's case where the reason for consult was an abrupt increase in mass size due to an infection.

There are four known types of this condition, the second branchial cleft anomaly being the most common ${ }^{4}$ comprising more than $90 \%$ of all branchial cleft anomalies. ${ }^{3}$ On physical examination, they appear as masses located anterior to the SCM at the below the mandible. ${ }^{4}$ The fistulous forms of this type extend from an external opening in the anterior neck coursing superiorly in between the in between the internal and external carotid arteries then travels up the level of the tonsillar fossa. ${ }^{5}$

Radiologic evaluation of this condition includes ultrasonography, CT scans and magnetic resonance imaging (MRI). 'The contrastenhanced CT scan of our patient identified 2 separate cystic masses. Histopathologic studies that showed epithilium-lined cysts are also consistent with the diagnosis.

Our patient presented with an infected second branchial cleft cyst. Recommended management consists of initial antibiotics followed by definitive surgery. The entire tract must be explored and removed to prevent recurrences. ${ }^{3}$ On surgical excision the mass was noted to have a dumbbell-shaped appearance with two (2) cystic structures connected by a tubular structure. Three other studies also reported similar presentations-- a double second branchial cleft cyst by MuñozFernández et al., ${ }^{6}$ a dumbbell - shaped 4th branchial cleft cyst by Kim et al. ${ }^{7}$ and two more cases of multiple branchial clefts reported in a study of 284 cases by Hu et al. 8

The definitive treatment for branchial cleft anomalies is surgical excision ideally up to the level of the tonsillar fossa., $\mathrm{3}$ fistulogram

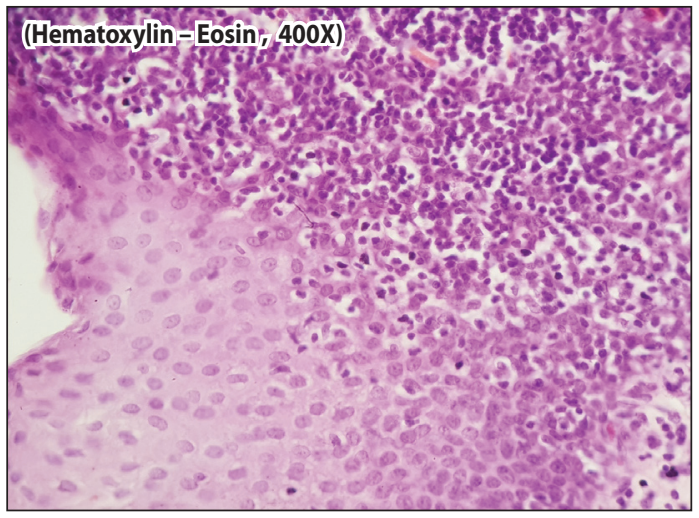

Figure 6. High power magnification of the excised mass under $\mathrm{H}$ \& $\mathrm{E}$ staining, showing the inner lining with lymphoid aggregates, and infiltration with mononuclear cells which represents chronic inflammation

can be used to follow the tract but is not absolutely necessary. ${ }^{10}$ Other methods may be used to follow the tract such as injecting methylene blue dye placing a catheter or using a wire probe on the external opening."

Our patient presented with a cyst that ended in a blind pouch at the level of the mandible and a tract could no longer be appreciated. Unusual presentations of such conditions may pose intraoperative surgical challenges and good preoperative evaluation as well as detailed imaging is necessary to ensure the complete and safe removal of this congenital mass.

\section{ACKNOWLEDGEMENTS}

We would like to thank Dr. Mark Jansen D.G. Austria for the details of the case and intraoperative pictures and Dr. Ivan De Guzman for interpreting the slides.

\section{REFERENCES}

1. Rizzi MD, Wetmore RF, Potsic WP. Differential Diagnosis of Neck Masses. In: Flint PW, Haughey BH, Lund VJ, Niparko JK, Robbins KT, Thomas JR, et al. (editors). Cummings Otolaryngology. 6th edition. Philadelphia, PA: Elsevier, Saunders. 2015. p. 3057.

2. Ahuja $A T$, King $A D$, Metreweli $C$. Second branchial cleft cysts: variability of sonographic appearances in adult cases. Am J Neuroradiol. 2000 Feb; 21(2): 315-319. PMID: 10696015.

3. Myers EN. Branchial Cleft Cyst and Sinuses. In: Myers EN, Carrau RL (editors). Operative Otolaryngology. Saint Louis: Elsevier Health Sciences. 2008. p.5-7.

4. Emerick K. Differential diagnosis of a neck mass. In Deschler DG, Sullivan DJ (editors). UpToDate [Last Updated 2016 May 16; Retrieved 2017 August 1]. Available from: https://www.uptodate com/contents/differential-diagnosis-of-a-neck-mass.

5. Chen EY, Sie KCY. Developmental Anatomy. In: Flint PW, Haughey BH, Lund VJ, Niparko JK, Robbins KT, Thomas JR, et.al. (editors). Cummings Otolaryngology. 6th edition. Philadelphia, PA: Elsevier, Saunders. 2015. p. 2823-28.

6. Muñoz-Fernández N, Mallea-Cañizares I, Fernández-Julián E, De La Fuente-Arjona L, MarcoAlgarra J. Double second branchial cleft anomaly. Acta Otorrinolaringol Esp. (English Edition). 2011 Jan-Feb; 62(1): 68-70. DOI: 10.1016/j.otorri.2010.01.008; PMID: 20236623.

7. Kim JY, Yoo YS, Choi JH, Cho KR. A Case of Non-Communicating Dumbbell Shaped Fourth Branchial Cleft Cyst. Korean Journal of Otolaryngology-Head and Neck Surgery. 2009; 52(2): 189-192. DOl: https://doi.org/10.3342/kjorl-hns.2009.52.2.189. [Korean], [Abstract available in english].

8. Hu YJ, Li YD, Qu XZ, Wang LZ, Zhong LP, Liu L, Zhang CP. [Clinical analysis of branchial cleft cyst (fistula): report of 284 cases]. Shanghai Kou Qiang Yi Xue. 2008 Oct; 17(5): 461-464. PMID: 18989583.

9. Fagan J.Resecting Branchial Fistulae, Sinuses and Cysts. The Open Access Atlas ofOtolaryngology, Head \& Neck Operative Surgery. [Retrieved 2017 Oct 11]. Available from: https://vula.uct.ac.za/ access/content/group/ba5fb1bd-be95-48e5-81 be-586fbaeba29d/Resecting\%20branchial\%20 cysts\%2C\%20fistulae\%20and\%20sinuses.pdf.

10. Rattan KN, Rattan S, Parihar D, Gulia JS, Yadav SP. Second branchial cleft fistula: is fistulogram necessary for complete excision. Int J Pediatr Otorhinolaryngol. 2006 Jun; 70(6); 1027-1030. DOl: 10.1016/j.jporl.2005.10.014; PMID: 16343647.

11. Houck J. Excision of Branchial Cysts. Operative Techniques in Otolaryngology. 2005; 16: 213-222. 